\title{
Update on the use of etanercept across a spectrum of rheumatoid disorders
}

\section{Bernard Combe}

Service d'Immuno-Rhumatologie, Montpellier, France
Correspondence: Bernard Combe Service d'Immuno-Rhumatologie, $\mathrm{CHU}$ Lapeyronie - 34295 Montpellier cedex 5, Université Montpellier I, Montpellier, France

Tel +33467338710

$\mathrm{Fax}+334673373$ II

Email b-combe@chu-montpellier.fr

\begin{abstract}
Etanercept is a soluble TNF receptor p75 fusion protein which is approved for subcutaneous use (50 mg weekly) in the treatment of patients with active rheumatoid arthritis (RA), juvenile RA, ankylosing spondylitis, and psoriatic arthritis. Etanercept binds to both TNF $\alpha$ and lymphotoxin and has quite a short mean half-life ( 70 hours). Numerous randomized clinical trials have demonstrated its efficacy to improve signs and symptoms in early and established RA and other inflammatory arthritis. Furthermore, etanercept has shown its ability to prevent radiographic progression and to improve health-related quality of life in patients with RA and psoriatic arthritis. A combination of etanercept plus methotrexate was more efficacious than etanercept monotherapy in RA patients but there is currently no evidence that such rheumatic combination is better than monotherapy in other disorders. Etanercept was generally well tolerated both in controlled trials with withdrawal rates being similar to the comparator groups and in large observational studies. Infections and injection-site reactions were the most frequently reported events. Serious infections were slightly increased but the occurrence of tuberculosis seemed less frequent than with anti-TNF monoclonal antibodies (infliximab and adalimumab). The benefit-risk ratio of etanercept appeared to be very positive, and this drug has now emerged as a major therapy in patients with active inflammatory arthritis. Furthermore, it is more frequently considered as an emerging and valuable option in patients with early disease.
\end{abstract}

Keywords: etanercept, TNF blockers, rheumatoid arthritis, juvenile rheumatoid arthritis, ankylosing spondylitis, psoriatic arthritis

Etanercept is a soluble dimeric fusion protein consisting of two copies of the extracellular ligand binding portion of the human tumor necrosis factor (TNF) p75 receptor linked to the constant portion (Fc) of human immunoglobulin G1. Etanercept binds specifically to $\mathrm{TNF} \alpha$, a proinflammatory cytokine, which plays a central role in the pathogenesis of different types of chronic inflammatory arthritis by exerting a number of effects that contribute to synovial and enthesitis inflammation and result in joint pathology (Choy and Panayi 2001; Culy and Keating 2002; Zhou 2005). Since it was licensed etanercept has dramatically improved the management and outcome of these chronic disorders as well as patient quality of life. Etanercept is currently approved both in Europe and in the US for subscutaneous use in the treatment of patients with moderate to severe active rheumatoid arthritis (RA), polyarticular juvenile RA, ankylosing spondylitis (AS), psoratic arthritis (PsA), and plaque psoriasis. In this review we will focus only on the use of etanercept in rheumatic diseases.

\section{Pharmacologic properties}

The pharmacologic profile of etanercept has been recently extensively reviewed (Culy and Keating 2002; Dhillon et al 2007). Etanercept binds to both TNF $\alpha$ and TNF $\beta$ (lymphotoxin), thereby blocking its interaction with cell surface receptors attenuating 
or preventing TNF-mediated pro-inflammatory effects and modulating the effect of other TNF-regulated molecules. The dimeric structure of etanercept means it can bind to two molecules of TNF $\alpha$ and is 50- to 1000 -fold more efficient than the monomeric soluble TNF receptor at neutralizing TNF $\alpha$ activity in vitro (Mohler et al 1993). Etanercept showed greater affinity for TNF than infliximab, a monoclonal antibody directed to TNF $\alpha$ (Davis et al 2002). In RA, etanercept reduced the level of pro-inflammatory cytokines and other soluble mediators such as interleukin 6 (IL-6), IL-1, and matrix-metalloproteinases, decreased the staining scores for CD3+ T cells, CD38+ plasma cells, and adhesion molecules, and decreased IL-1 $\beta$ expression and accumulation of chemokine receptor-positive $\mathrm{T}$ cells. These changes were correlated with improvement in disease activity (Culy and Keating 2002). Etanercept has also been shown to increase bone formation and decrease bone resorption, suggesting a joint protective effect (Soriolo et al 2006). In several studies, etanercept did not have adverse effects on global immune function.

Anti-etanercept nonneutralizing antibodies were detected in some patients who where on etanercept therapy. However, their development was not correlated with blood level of the drug or with clinical efficacy or adverse events. Autoantibodies have been detected in etanercept-treated patients but their frequency appeared to be lower than with infliximab treatment and did not appear to be correlated with clinical symptoms such as lupus-like syndromes (Culy and Keating 2002; Dhillon et al 2007).

The pharmacokinetic parameters in patients with RA are summarized in Table 1.

After subcutaneous injection, etanercept is slowly absorbed, with mean peak serum concentration reached between 53 and 62 hours after repeated administration. The drug appears to be widely distributed, including into the synovium. It is slowly cleared from the body with an elimination half-life

Table I Pharmacokinetic properties of etanercept in rheumatoid arthritis patients receiving multiple dose of subcutaneous etanercept

\begin{tabular}{lll}
\hline Parameter & $\begin{array}{l}\mathbf{2 5} \mathbf{~ m g} \text { biw } \\
\text { (EMEA) }\end{array}$ & $\begin{array}{l}\mathbf{5 0 ~} \mathbf{~ m g ~ q w} \\
\text { (Nestorov 2004) }\end{array}$ \\
\hline $\mathrm{C}_{\max }(\mathrm{mg} / \mathrm{L})$ & 2.6 & 2.4 \\
$\mathrm{C}_{\min }(\mathrm{mg} / \mathrm{L})$ & 1.4 & 1.2 \\
$\mathrm{~T}_{\max }(\mathrm{h})$ & 62 & 53 \\
$\mathrm{AUC}(\mathrm{mg} . \mathrm{h} / \mathrm{L})$ & 316 & 297 \\
$\mathrm{~T} 1 / 2(\mathrm{~h})$ & $70-$ & 100 \\
\hline
\end{tabular}

Abbreviations: AUC, area under the concentration-time curve; biw, twice weekly; $q w$, once weekly; $C_{\text {max }}$, maximum serum concentration; $t_{\max }$, time to reach $C_{\max } ; T 1 / 2$, elimination half-life. of 70 hours (30-300) in patients with RA. After binding to TNF $\alpha$, the etanercept-TNF complex is probably metabolized by proteolytic processes, before recycling or elimination in the urine or bile (Zhou 2005). The steady-state concentrationtime profile is similar for $50 \mathrm{mg}$ once-weekly and $25 \mathrm{mg}$ twice-weekly administration (Nestorov et al 2004). The pharmacokinetic properties of etanercept are not affected by gender, age or ethnicity, heart failure, or renal insufficiency. They are also not altered with concomitant administration of methotrexate (MTX) or warfarin.

\section{Therapeutic efficacy in adult patients with rheumatoid arthritis}

Therapeutic efficacy of etanercept in RA has been reviewed in detail (Culy and Keating 2002; Dhillon et al 2007). This efficacy has been evaluated by several well-designed trials both in late and early disease (Table 2). In addition, extensions of these short-term trials and several large observational studies have evaluated its long-term efficacy and its use in clinical practice. As it is recommended for the development of an efficient drug in RA, etanercept has demonstrated clear efficacy in clinical and radiographic measurement and on patient perspective (eg, quality of life measures). In most of the clinical trials, etanercept was administred twice weekly.

\section{Efficacy in patients with established RA}

Efficacy of etanercept was first demonstrated in established RA, in patients who previously failed on traditional diseasemodifying anti-rheumatic drugs (DMARDs). More than 90\% of these patients had $\geq 2$ years' disease duration. Eligible patients had active RA ( $\geq 6-10$ swollen joints; $\geq 6-12$ tender joints) and were receiving a stable dosage of MTX, sulfasalazine, gold, or hydroxychloroquine for 4-6 weeks. When no treatment with DMARDs was permitted, a 4-week wash-out period was required.

\section{Clinical response in monotherapy}

In a 3-month phase II trial in patients for whom 4 DMARDs had failed, there was a dose-dependent improvement in all primary and efficacy variables in patients receiving 0.25-16 mg twice weekly etanercept (Moreland et al 1997). At the higher dosage, $75 \%$ and $57 \%$ of the patients achieved ACR 20 and ACR 50 responses by 3 months versus 14\% and $7 \%$, respectively, in the placebo group. In both this trial and a phase III trial (Moreland et al 1999), patients experienced a rapid response to etanercept with differences relative to placebo at week 2 . In the phase III trial, a significantly higher percentage of patients treated with etanercept (10 or $25 \mathrm{mg}$ 
Table 2 Efficacy of etanercept (ETN) in controlled trials versus methotrexate (MTX) or placebo (PBO) in patients with rheumatoid arthritis (RA)

\begin{tabular}{|c|c|c|c|c|c|c|c|}
\hline \multirow[t]{2}{*}{ Reference } & \multirow[t]{2}{*}{ Treatment } & \multirow{2}{*}{$\begin{array}{l}\text { nr } \\
\text { patients }\end{array}$} & \multirow{2}{*}{$\begin{array}{l}\text { Time point } \\
\text { (months) }\end{array}$} & \multicolumn{4}{|c|}{ Clinical response (\% patients) } \\
\hline & & & & $\begin{array}{l}\text { ACR } \\
20\end{array}$ & $\begin{array}{l}\text { ACR } \\
50\end{array}$ & $\begin{array}{l}\text { ACR } \\
70\end{array}$ & $\begin{array}{l}\text { DAS } \\
\text { remission }\end{array}$ \\
\hline \multicolumn{8}{|l|}{ Established RA } \\
\hline \multirow[t]{4}{*}{ Moreland et al 1997} & ETN* $0.25 \mathrm{mg} / \mathrm{m}^{2}$ & 180 & 3 & 33 & 9 & & \\
\hline & ETN* $2 \mathrm{mg} / \mathrm{m}^{2}$ & & & 46 & 22 & & \\
\hline & ETN* $16 \mathrm{mg} / \mathrm{m}^{2}$ & & & $75^{\mathrm{a}}$ & $57^{\mathrm{a}}$ & & \\
\hline & PBO & & & 14 & 7 & & \\
\hline \multirow[t]{3}{*}{ Moreland et al 1999} & ETN* $10 \mathrm{mg}$ & 234 & 6 & $5 I^{a}$ & $24^{a}$ & & \\
\hline & ETN* $25 \mathrm{mg}$ & & & $59^{a}$ & $40^{\mathrm{a}}$ & & \\
\hline & PBO & & & 11 & 5 & & \\
\hline \multirow[t]{2}{*}{ Weinblatt et al 1999} & $\mathrm{ETN}^{* *}+\mathrm{MTX}$ & 89 & 6 & $7 I^{c}$ & $39^{c}$ & $15^{\mathrm{b}}$ & \\
\hline & MTX + PBO & & & 27 & 3 & 0 & \\
\hline \multirow[t]{2}{*}{ van Riel et al 2006} & $\mathrm{ETN}^{* *}+\mathrm{MTX}$ & 314 & 4 & 67 & 40 & 18 & \\
\hline & ETN** & & & 71 & 42 & 17 & \\
\hline \multirow[t]{3}{*}{ Kloreskog et al 2004} & $E T N^{* *}+M T X$ & 682 & 12 & $85^{\mathrm{b}, \mathrm{e}}$ & $69^{\mathrm{d}, \mathrm{f}}$ & $43^{\mathrm{d}, \mathrm{f}}$ & $35^{\mathrm{d}, \mathrm{f}}$ \\
\hline & $\mathrm{ETN}^{* *}+\mathrm{PBO}$ & & & 76 & 48 & 24 & 16 \\
\hline & $\mathrm{MTX}+\mathrm{PBO}$ & & & 75 & 43 & 19 & 13 \\
\hline \multicolumn{8}{|l|}{ Early RA } \\
\hline \multirow[t]{3}{*}{ Bathon et al 2006} & ETN 10 & 632 & 12 & 60 & 34 & 16 & \\
\hline & ETN 25 & & & 72 & 49 & 25 & \\
\hline & MTX & & & 65 & 43 & 22 & \\
\hline Genovese et al 2002 & ETN 10 & 512 & 24 & 61 & 35 & 19 & \\
\hline \multirow[t]{2}{*}{ (Extension study) } & ETN 25 & & & $72^{\mathrm{b}}$ & 49 & 29 & \\
\hline & MTX & & & 59 & 42 & 24 & \\
\hline \multirow[t]{2}{*}{ Emery et al 2007} & ETN + MTX & 528 & 12 & $86^{c}$ & $7 I^{c}$ & $48^{c}$ & 50 \\
\hline & MTX & & & 67 & 49 & 28 & 28 \\
\hline
\end{tabular}

*Twice weekly

**ETN 25 mg twice weekly

${ }^{\mathrm{a}} \mathrm{p}<0.001$ vs $\mathrm{PBO}$

${ }^{\mathrm{b}} \mathrm{P}<0.05$ vs MTX

${ }^{c} \mathrm{p}<0.00$ I vs MTX

${ }_{\mathrm{P}}^{\mathrm{d}}<0.000$ I vs MTX

${ }^{\mathrm{e}} \mathrm{p}<0.05$ vs ETN

${ }^{\mathrm{f}} \mathrm{p}<0.000$ I vs ETN

twice weekly) achieved ACR 20, 50, and 70 responses compared with placebo both at 3 and 6 months, with a trend in favor of the $25 \mathrm{mg}$ dosage. Most of the single variables of disease activity including swollen and tender joints counts, ESR, and CRP, were also improved compared with placebo. Long-term extension studies (up to 10 years) showed a sustained clinical efficacy (Dhillon et al 2007).

Health-related quality of life (HR-QOL), assessed by HAQ score or SF-36, was also improved in the etanercept groups compared with controls at 3 and 6 months but also in long-term extension studies (Moreland et al 1997, 1999, 2006; Mathias et al 2000).

\section{Clinical response in combination with methotrexate}

Two main randomized, double-blind trials have demonstrated the clinical efficacy of etanercept plus MTX combination in patients with late RA (Weinblatt et al 1999; Klareskog et al 2004). In patients with inadequate response to MTX, combination therapy was more effective than MTX plus placebo with $66 \%$ and $71 \%$ of ACR 20 responders in the etanercept plus MTX group respectively at 3 and 6 months versus 33 and $27 \%$ in the control group (Weinblatt et al 1999). The TEMPO trial (Klareskog et al 2004) was a 3-year randomized doublestudy which compared etanercept monotherapy versus MTX therapy and etanercept plus MTX. At 6 months, the primary endpoint showed that the AUC ACRn in the combination group was greater compared with the MTX group (18.3\% years vs $12.2 \%$ years; $p<0.0001$ ) with also a significant difference between the etanercept and MTX groups $(14.7 \%$ years vs $12.2 ; \mathrm{p}=0.0034)$. At 6 and 12 months, $83 \%$ and $85 \%$, respectively, of patients in the combination group achieved an ACR 20 response significantly greater than in 
the two monotherapy groups. Similar data were obtained for ACR 50 and 70 and DAS 28 score responses. At these evaluations, there was no difference in ACR responses between the two monotherapy groups. In addition, after 1 year of treatment, the proportion of patients achieving DAS 28 remission was significantly higher in the combination group versus etanercept and MTX groups (35\% vs $16 \%$ vs $13 \%$; all $\mathrm{p}<0.0001)$. In the 2 - and 3 -year evaluations of the TEMPO trial, the combination of etanercept plus MTX was significantly better than etanercept or MTX monotherapies on all measures of disease activity (van der Heijde et al 2006a, 2007). Of the patients, $38.7 \%, 26.7 \%$, and $23.6 \%$ achieved DAS 28 remission at 3 years respectively in the combination, the etanercept, and the MTX groups, respectively. In extension studies ( $>3$ years) efficacy of etanercept plus MTX was sustained in the TEMPO trial and in patients with inadequate response to MTX (Kremer et al 2003).

The ADORE (ADd etanercept Or Replace MTX) trial was a 6-month open-label trial in patients with inadequate response to MTX ( $\geq 3$ months) (van Riel et al 2006). Patients were randomized to switch MTX with etanercept or to add etanercept to MTX. By 6 months, there was a significant improvement in both groups but no difference in any of the measurements of disease activity between the two groups.

HR-QOL measures at 12 months were better improved during the TEMPO trial in the etanercept plus MTX combination than in the monotherapy groups. In addition, more patients receiving combination therapy than both monotherapies had HAQ scores of $\leq 0.5$ and achieved a clinically significant improvement of HAQ disability $(H A Q \geq 0.22)(p<0.05)$ (van der Heijde et al 2006b). Patient satisfaction with medication was higher in the combination than in the MTX monotherapy group ( $p<0.0001$ ) without significant difference between combination and etanercept monotherapy (van der Heijde et al 2006b). Similar trends on HR-QOL measures were observed at 2 and 3 years (van der Heijde et al 2006a, 2007).

\section{Clinical response in combination with other DMARDs}

A double-blind randomized study compared the effect of etanercept alone or in combination with sulfasalazine (SSZ) in patients with active RA and inadequate response to SSZ (Combe et al 2006). ACR 20 response rates at 24 weeks were significantly higher for etanercept plus SSZ and etanercept monotherapy than SSZ alone (respectively $73.8 \%, 74.0 \%$ vs $28 \%$; p $<0.01)$. The two etanercept groups did not differ. Similar trends were seen for ACR 50 and 70 responses at 24 weeks. A 2 years, the extension study showed similar results. No controlled trials evaluating the combination of etanercept and leflunomide are available; however, observational studies suggested that this combination could be an alternative option.

\section{Radiography efficacy}

The TEMPO trial demonstrated that etanercept was effective in preventing radiographic progression of patients with established RA (Klareskog et al 2004; van der Heijde et al 2006a, 2007). At 1 year, the van der Heijde modified total Sharp Score (mTSS), and erosion and joint-space narrowing (JSN) scores had less progression in the etanercept plus MTX combination therapy than in the MTX monotherapy group $(\mathrm{p}<0.0001)$. There was also less progression for mTSS and JSN score in the combination group than in the etanercept monotherapy group $(p<0.01)$ and less progression for mTSS and erosion score in the etanercept monotherapy group than in the MTX group $(p=0.046)$. The percentage of patients without radiographic progression was higher in the combination therapy group ( $80 \%$ ) than in the two monotherapy groups $(\mathrm{p}<0.005)$ and higher in the etanercept $(68 \%)$ than in the MTX group ( $57 \% ; p=0.02)$. Furthermore, at 2 and 3 years, there was significantly less structural progression in the combination group and less progression in patients receiving etanercept monotherapy than MTX monotherapy.

\section{Efficacy in patients with early rheumatoid arthritis}

A double-blind randomized study evaluated etanercept monotherapy versus MTX in MTX-naïve patients with early RA at risk of disease progression (Bathon et al 2000). Etanercept patients have a more rapid response to treatment than MTX group as evaluated by AUC ACRn ( $<<0.05)$. However, no statistical differences on ACR responses between the two groups were seen at 6- and 12-month evaluations. Extension study shows that the rate of ACR 20 responders was higher in etanercept $25 \mathrm{mg}$ than in MTX group after 2 years. Etanercept patients experienced more rapid improvement in HR-QOL parameters as assessed by SF-36 and HAQ score, although there was no between-group difference from 4 months onward (Bathon et al 2000).

The progression of the mTSS was lower at 6 months in the etanercept group but the difference with MTX-treated patients was not significant at one year (Genovese et al 2002, 2005). However, the mean change in erosion scores from baseline was smaller in etanercept than in MTX group both at 6 and 12 months. At 2 years, radiographic progression of both mTSS and erosion scores was reduced in the etanercept 
versus MTX patients $(\mathrm{p}<0.02)$. The rate of patients with no progression was higher in the etanercept group at 1 and 2 years.

The recent COMET study (Emery et al 2007) was designed to evaluate the DAS28 remission rate obtained after 1 and 2 years of therapy in 528 patients with early RA $(<2$ years disease duration) receiving etanercept plus MTX or MTX alone. At week 52, $50 \%$ of patients on etanercept plus MTX achieved remission versus $28 \%$ on MTX alone $(\mathrm{p}<0.001)$. Low disease activity (DAS28 $\leq 3.2$ ) was achieved by $64 \%$ and $41 \%$ of patients in the etanercept plus MTX and MTX groups respectively $(\mathrm{p}<0.001)$. Percentage of patients who were ACR 20 (86\% vs 67\%), ACR 50 (71\% vs 49\%) and ACR $70(48 \%$ vs $28 \%)$ responders at week 52 were also statistically different between groups ( $\mathrm{p}<0.001$ ). The cumulative work days missed was also lower (15.0 vs 4.8$)$ in the etanercept plus MTX group $(\mathrm{p}<0.05)$.

\section{Therapeutic efficacy in juvenile rheumatoid arthritis (JRA)}

The efficacy of etanercept monotherapy in reducing disease activity in young patients with JRA was demonstrated in a 2-part trial which included a 3-month open trial then a 4-month double-blind, placebo-controlled phase (Lovell et al 2000). Sixty-nine children who had an inadequate response to MTX were enrolled; 40 of them had polyarticular arthritis and $22 \mathrm{had}$ systemic arthritis. After 3 months of treatment with etanercept (0.4 mg/kg twice weekly), 51 patients (74\%) and 25 (36\%) experienced pediatric ACR 30 and 70 responses. All the patients who achieved the ACR 30 response were randomized to receive placebo or etanercept. After 4 months of therapy, disease flare was observed in $81 \%$ in the placebo group compared with $28 \%$ of those receiving etanercept $(\mathrm{p}=0.003)$. The median time to flare was longer in patients receiving etanercept (116 vs 28 days; $\mathrm{p}<0.001)$. An open label extension trial showed a sustained efficacy of etanercept after 2 and 4 years (Lovell et al 2003, 2006). Of the 58 patients who enrolled in the extension study, 34 patients received etanercept treatment for $\geq 4$ years and 32 of these showed complete efficacy assessments. Furthermore, $94 \%$ and $78 \%$ achieved pediatric ACR 30 and 70 respectively at the last study visit (Lovell et al 2006). Several other nonblind or observational studies supported the effect of etanercept in JRA (Culy and Keating 2002).

\section{Therapeutic efficacy in ankylosing spondylitis}

Three randomized controlled trials have demonstrated strong efficacy of etanercept monotherapy in patients suffering from AS (Davis et al 1995; Gorman et al 2002; Calin et al 2004; Hoy and Scott 2007). These trials showed rapid and sustained improvement of spinal pain, global disease activity, and function as assessed by Bath Ankylosing Spondylitis Disease Activity Index (BASDAI) and Bath Ankylosing Spondylitis Functional Index (BASFI) and HR QOL assessed by SF-36 scale after 24 and 102 weeks. Metrology index (BASMI) was also improved. The improvement was usually seen within 2 weeks of therapy associated with a rapid decrease of CRP.

As an example in the 24 weeks study by Davis et al (1995), 277 patients were randomized to receive etanercept (25 mg twice weekly) or placebo. The rate of ASAS 20 responders which was the primary endpoint was highly significantly different between the two groups $(\mathrm{p}<0.0001)$. The percentage of patients who improved the BASDAI score by more than $50 \%$ were also significantly in favor of etanercept as well as the rapid decrease of CRP level (Davis et al 1995; Gorman et al 2002; Calin et al 2004). After several months without etanercept, patients had had a disease flare but reintroduction of the therapy was effective (Brandt et al 2005). Etanercept efficacy was also suggested in undifferentiated spondylarthropathies (Brandt et al 2004).

In addition, the clinical efficacy of etanercept was also supported by improvement of active spinal inflammation as detected by MRI (Baraliakos et al 2005a). Finally, clinical and MRI efficacy on enthesitis have also been shown in one study (Baraliakos et al 2005b). However, whether etanercept treatment was able to control radiographic progression has not been demonstrated. Patients with early disease, or elevated CRP, or positive MRI inflammation, or minimal structural abnormalities seemed to be more likely to respond than patients with late and advanced disease (Rudwaleit et al 2004) but all patient types could benefit from etanercept therapy. There is no indication that combination with MTX may provide additional benefit.

Effectiveness of etanercept in the prevention and treatment of anterior uveitis has also been shown (Braun et al 2005) whereas effect on gut symptoms of inflammatory bowel disease is unlikely at the tested dosages (Braun et al 2007).

\section{Therapeutic efficacy in psoriatic arthritis}

Two double-blinded placebo-controlled trials evaluated the effect of etanercept ( $25 \mathrm{mg}$ twice weekly) in patients suffering from PsA (Mease et al 2000; 2004; Woolacott et al 2006; Hoy and Scott 2007). In both trials, the 12 weeks (Mease et al 2000) or 24 weeks (Mease et al 2004) controlled 
phase was followed by an open-label follow-up in which all patients received etanercept. PsA response criteria response was achieved by $87 \%$ and $70 \%$ of the patients at endpoint in the etanercept group versus $23 \%$ in the placebo group in both studies. ACR 20, 50 and 70 responses were also achieved by significantly more patients in the etanercept group. There was no indication that concomitant MTX use provides an additional effect to etanercept alone. The effect on psoriasis was also in favor of etanercept based on PASI 75 and PASI 50 at week 12 and 24. Radiographic assessment was available at 24 weeks and showed that disease progression as assessed by mTSS was significantly lower in patients treated with etanercept compared with the placebo group (Mease et al $2004)$ and at 1 year, the mean annualized rate $(-0.03)$ of radiographic progression indicated no significant progression of joint erosions for all etanercept patients.

\section{Safety of etanercept in rheumatic disorders}

Etanercept was generally well tolerated in the different clinical trials that were reported above in the efficacy sections whatever the rheumatic diseases where it was evaluated. Safety data are also supported by long term extension studies, by several national registries both in EU and in the US (Setoguchi et al 2006; Strangfeld and Listing 2006; Askling et al 20007; Carmona et al 2007; Dixon et al 2007a; Jacobsson et al 2007; Michaud and Wolfe 2007; Schneeweiss et al 2007; Wolfe and Michaud 2007) and by reports from the US and European agencies. Furthermore, more than 1 million patient-years have been exposed to etanercept all over the world.

In the controlled trials, the rate of discontinuation linked to treatment-related adverse events was not significantly increased in patients receiving etanercept. Severity of adverse events was generally mild to moderate. The most frequent adverse events reported in patients receiving etanercept were infections and injection-site reactions. Addition of methotrexate or other DMARD did not seem to increase the rate of side-effects related to etanercept. By contact, the combination with other biological therapy such as anakinra (Genovese et al 2004) or abatacept (Weinblatt et al 2006) increased the incidence of infections and is not recommended.

\section{Injection-site reactions}

The incidence of injection-site reactions was higher in etanercept treated patients than in control groups. They were usually mild including pain, itching, and erythema and generally did not require drug discontinuation. The frequency of these reactions varied widely across the studies and usually occurred during the first weeks of therapy.

\section{Infections}

Infections were the most frequently reported adverse events in the clinical trials but without significant differences between etanercept and control groups. Serious infections, by contrast, were more frequently reported both in controlled trials and in observational studies in patients treated with etanercept with an odd-ratio around two compared with patients treated with nonbiologic anti-rheumatic therapies such as methotrexate or other DMARDs. There is no evidence that the frequency of serious infections with etanercept could be different to that observed with other TNF blockers. Consistent data from observational studies suggested that the rate of serious infections could be mainly increased during the first 6 months of therapy (Askling et al 2007; Dixon et al 2007a). Upper respiratory tract infections, sinusitis, urinary tract infections, and soft tissues infections were the most commonly reported infections. In open-extension trials of $\leq 8.2$ years' duration, the incidence of serious infections was 2.0-4.2 events/100 patient-years (Kremer et al 2003; Moreland et al 2006; Genovese et al 2005). Rare but severe opportunistic infections including tuberculosis have also been observed. Similarly to other TNF blockers, the occurrence of tuberculosis appeared to be due to reactivation of latent tuberculosis. However, there have been more reported cases of tuberculosis in individuals treated with infliximab and adalimumab than using etanercept and there are now consistent data suggesting that the risk of reactivation of latent tuberculosis is significantly lower with etanercept than with monoclonal antibodies (Furst et al 2006, 2007; Tubach et al 2007). Screening of patients and antibioprophylaxis before starting anti-TNF therapy has reduced the risk of activating tuberculosis (Carmona et al 2005) and is recommended with the three drugs (Furst et al 2007). Recent data from the German registry have also suggested that the occurrence of herpes virus and herpes zoster infections may be lower in patients using etanercept than adalimumab or infliximab (Strangfeld et al 2007).

In hepatitis $\mathrm{C}$, observational studies and one controlled trial showed that etanercept did not have an effect on viral load and there was no increase in incidence of adverse effects (Khanna et al 2003). In hepatitis B, patients treated with all three anti-TNF agents have experienced increased symptoms and worsening of viral load (Furst et al 2007). Consequently, TNF blockers should not be used in patients with known hepatitis B infection; in hepatitis C, etanercept 
may be prescribed but with tight control in patients with viral load (Furst et al 2007).

Etanercept does not significantly influence the development of protective antibodies after vaccination (Kapetanovic et al 2007). Vaccination with live attenuated vaccines is contra-indicated as with other immunosuppressive medications.

\section{Malignancies}

There are still conflicting data about whether or not there is an increased risk for lymphoma and solid tumors with antiTNF agents. Several large observational databases and a case control study did not demonstrate an increased incidence of malignancies in patients receiving anti-TNF therapies (Setoguchi et al 2006; Dhillon et al 2007; Jacobsson et al 2007; Wolfe and Michaud 2007; Furst et al 2007). Only the risk of nonmelanoma skin cancer might be increased (Furst et al 2007; Wolfe and Michaud 2007).

The incidence of malignancies that has been reported in etanercept recipients during clinical trials and post-marketing surveillance was not different to that expected in the general population (EMEA; Okada and Siegel 2006). However, vigilance with respect to the occurrence of malignancies including recurrence of solid tumors remains warranted in patients using etanercept and other TNF blockers.

\section{Other adverse events}

A low percentage of patients receiving etanercept may develop autoantibodies including anti-nuclear antibodies, anti-double-stranded DNA antibodies, and anti-cardiolipin antibodies; however, there is no evidence that these patients are at significantly increased risk for the development of clinical symptoms (Dhillon et al 2007; Furst et al 2007). Rare cases of drug-induced lupus have been observed with the three anti-TNF agents (Furst et al 2007).

Around 5\% of patients developed nonneutralizing antietanercept antibodies which did not seemed to affect the efficacy and the safety of the drug (EMEA). Allergic reactions including angio-edema and urticaria have been described in etanercept-treated patients. Rare cases of central nervous system demyelinating disorders or pancytopenia or aplastic anemia have been also reported. Worsening of congestive heart failure (CHF) has been associated with anti-TNF therapy, mainly in patients treated with high dose infliximab, but there is presently no evidence that etanercept $50 \mathrm{mg} /$ week increases the incidence of CHF or CHF mortality (Khanna et al 2004). There is no evidence that etanercept may have a negative effect during pregnancy; however, there is currently insufficient information to safely counsel the continuation of any TNF blocker during pregnancy (Furst et al 2007).

\section{Conclusion}

Subcutaneous etanercept (50 mg once weekly or $25 \mathrm{mg}$ twice weekly) has emerged as a major new therapy in a large spectrum of inflammatory rheumatic disorders including rheumatoid arthritis, juvenile rheumatoid arthritis, ankylosing spondylitis, and psoriatic arthritis. Etanercept has demonstrated significant clinical efficacy compared to control in these diseases and has shown its ability to stop or prevent radiographic progression of joint damage in patients with rheumatoid arthritis or psoriatic arthritis. Combination of etanercept plus methotrexate has shown a greater efficacy than etanercept monotherapy in rheumatoid arthritis patients but there is no clear evidence that adding etanercept is more efficient than switching to etanercept in patients with inadequate response to methotrexate. Etanercept is generally well tolerated and the safety of the drug has been reassured by data from clinical trials, long-term observational studies and post-marketing surveillance with almost 10 years of use in clinical practice.

Etanercept has shown some advantages to other TNF blockers including safety (tuberculosis, herpes zoster), absence of significant development of neutralizing antibodies, and some better evidence of efficacy when used in monotherapy in patients with rheumatoid arthritis.

Etanercept is usually recommended to be used as a second line agent in patients with active inflammatory arthritis and inadequate response to standard therapy. However, etanercept can be proposed as first DMARD in combination with methotrexate in patients with early rheumatoid arthritis with very active disease and/or high risk of developing severe disease (Combe 2007; Combe et al 2007; Fautrel et al 2007; Furst et al 2007). In patients with early rheumatoid arthritis, etanercept in combination with methotrexate has demonstrated a high rate of responders and a high rate of disease remission and is now considered as an emerging option in these patients.

Recent evidence has suggested that etanercept and other TNF blockers may reduce the risk of cardiovascular disease, mortality (Jacobsson et al 2007 Dixon et al 2007b), and the need for joint surgery in patients with rheumatoid arthritis and may also be cost-effective from a societal perspective, but further research is needed to confirm these important issues.

\section{Disclosures}

The author has been consultant and/or speaker for Abbott, BMS, MSD, Roche, Schering, UCB, and Wyeth. 


\section{Abbreviations}

ACR, American College of Rheumatology; ACR 20, ACR 50, ACR 70: $20 \%, 50 \%$, or $70 \%$ of patients respond to ACR response criteria for rheumatoid arthritis; ASAS, Assessment in ankylosing spondylitis; AUC, area under the curve; BASDAI, Bath Ankylosing Spondylitis Disease Activity Index; BASFI: Bath Ankylosing Spondylitis Functional Index; CRP, C-reactive protein; DAS, disease activity score; DAS 28, disease activity score on 28 joints; DMARDs, disease modifying anti-rheumatic drugs; ESR, erythrocyte sedimentation rate; HAQ, Health Assessment Questionnaire; HR-QOL, health related quality of life; MTX, methotrexate; SF-36, 36-Item Short Form Health Survey; TNF, tumor necrosis factor.

\section{References}

Askling J, Fored CM, Brandt L, et al. 2007. Time-dependent increase in risk of hospitalisation with infection among Swedish RA patients treated with TNF antagonists. Ann Rheum Dis, 66:1339-44.

Baraliakos X, Brandt J, Listing J, et al. 2005b. Outcome of patients with active ankylosing spondylitis after two years of therapy with etanercept: clinical and magnetic resonance imaging data. Arthritis Rheum, 53:856-63.

Baraliakos X, Davis J, Tsuji W, et al. 2005a. Magnetic resonance imaging examinations of the spine in patients with ankylosing spondylitis before and after therapy with the tumor necrosis factor alpha receptor fusion protein etanercept. Arthritis Rheum, 52:1216-23.

Bathon JM, Martin RW, Fleischmann RM, et al. 2000. A comparison of etanercept and methotrexate in patients with early rheumatoid arthritis. N Engl J Med, 343:1586-93.

Brandt J, Khariouzov A, Listing J, et al. 2004. Successful short term treatment of patients with severe undifferentiated spondyloarthritis with the anti-tumor necrosis factor-alpha fusion receptor protein etanercept. J Rheumatol, 31:531-8.

Brandt J, Listing J, Haibel H, et al. 2005. Long-term efficacy and safety of etanercept after readministration in patients with active ankylosing spondylitis. Rheumatology (Oxford), 44:342-8.

Braun J, Baraliakos X, Listing J, et al. 2005. Decreased incidence of anterior uveitis in patients with ankylosing spondylitis treated with the anti-tumor necrosis factor agents infliximab and etanercept. Arthritis Rheum, 52:2447-51.

Braun J, Baraliakos X, Listing J, et al. 2007. Differences in the incidence of flares or new onset of inflammatory bowel diseases in patients with ankylosing spondylitis exposed to therapy with anti-tumor necrosis factor alpha agents. Arthritis Rheum, 57:639-47.

Calin A, Dijkmans B, Emery P, et al. 2004. Outcomes of a multicentre randomised trial of etanercept to treat ankylosing spondylitis. Ann Rheum Dis, 63:1594-600.

Carmona L, Descalzo MA, Perez-Pampin E, et al. 2007. All-cause and cause-specific mortality in rheumatoid arthritis are not greater than expected when treated with tumour necrosis factor antagonists. Ann Rheum Dis, 66:880-5.

Carmona L, Gómez-Reino JJ, Rodríguez-Valverde V, et al. 2005. Effectiveness of recommendations to prevent reactivation of latent tuberculosis infection in patients treated with tumor necrosis factor antagonists. Arthritis Rheum, 52:1766-72.

Choy EN, Panayi GS. 2001. Cytokine pathways and joint inflammation in rheumatoid arthritis. $N$ Engl J Med, 344:907-16.

Combe B, Codreanu C, Fiocco U, et al. 2006. Etanercept and sulfasalazine, alone and combined, in patients with active rheumatoid arthritis despite receiving sulfasalazine: a double-blind comparison. Ann Rheum Dis, $65: 1357-62$
Combe B, Landewe R, Lukas C, et al. 2007. EULAR recommendations for the management of early arthritis: report of a task force of the European Standing Committee for International Clinical Studies Including Therapeutics (ESCISIT). Ann Rheum Dis, 66:34-45.

Combe B. 2007. Early rheumatoid arthritis: strategies for prevention and management. Best Pract Res Clin Rheumatol, 21:27-42

Culy CR, Keating GM. 2002. Etanercept. An updated review of its use in rheumatoid arthritis, psoriatic arthritis and juvenile rheumatoid arthritis. Drugs, 62:2493-2537.

Davis JC Jr, van der Heijde DM, Braun J, et al. 1995. Use of immunohistologic and in situ hybridization techniques in the examination of sacroiliaque joint biopsy specimens from patients with ankylosing spondylitis. Arthritis Rheum, 38:499-505.

Davis T, Friend D, Smith CA. 2002. Comparative TNF binding characteristics of etanercept (Enbrel) and infliximab (Remicade). Ann Rheum Dis, 61(Suppl 1): 184 .

Dhillon S, Lyseng-Williamson KA, Scott LJ. 2007. Etanercept: A review of its use in the management of rheumatoid arthritis. Drugs, 67:1211-41.

Dixon WG, Symmons DP, Lunt M, et al. 2007a. Serious infection following anti-tumor necrosis factor alpha therapy in patients with rheumatoid arthritis: lessons from interpreting data from observational studies. Arthritis Rheum, 56:2896-904.

Dixon WG, Watson KD, Lunt M, et al. 2007b. Reduction in the incidence of myocardial infarction in patients with rheumatoid arthritis who respond to anti-tumor necrosis factor $\alpha$ therapy: results from the British Society for Rheumatology Biologics Register. Arthritis Rheum, 56:2905-12.

Emery P, Breedveld F, Hall S, et al. Remission rates in subjects with active early rheumatoid arthritis. 1 year results of the COMET trial: combination of methotrexate and etanercept in active early rheumatoid arthritis. ACR Scientific Meeting, Boston, November 6-11, 2007. Late-Breaking Abstracts, L17.

[EMEA] European Medicines Agency. Enbrel 25 and $50 \mathrm{mg}$ solution for injection: summary of product characteristics [online]. URL: http:// www.emea.europa.eu.

Fautrel B, Pham T, Mouterde G, et al. 2007. Recommendations of the French Society for Rheumatology regarding TNFalpha antagonist therapy in patients with rheumatoid arthritis. Joint Bone Spine, 74:627-37.

Furst DE, Breedveld FC, Kalden JR, et al. 2007. Updated consensus statement on biological agents for the treatment of rheumatic diseases, 2007. Ann Rheum Dis, 66(Suppl 3):iii2-22.

Furst DE, Wallis R, Broder M, et al. 2006. Tumor necrosis factor antagonists: different kinetics and/or mechanisms of action may explain differences in the risk for developing granulomatous infection. Semin Arthritis Rheum, 36:159-67.

Genovese MC, Bathon JM, Fleischmann RM, et al. 2005. Longterm safety, efficacy, and radiographic outcome with etanercept treatment in patients with early rheumatoid arthritis. $J$ Rheumatol, 32:1232-42.

Genovese MC, Bathon JM, Martin RW, et al. 2002. Etanercept versus methotrexate in patients with early rheumatoid arthritis: two-year radiographic and clinical outcomes. Arthritis Rheum, 46:1443-50.

Genovese MC, Cohen S, Moreland L, et al. 2004. Combination therapy with etanercept and anakinra in the treatment of patients with rheumatoid arthritis who have been treated unsuccessfully with methotrexate. Arthritis Rheum, 50:1412-9.

Gorman JD, Sack KE, Davis JC Jr. 2002. Treatment of ankylosing spondylitis by inhibition of tumor necrosis factor alpha. $N$ Engl $J$ Med, 346:1349-56.

Hoy SM, Scott LJ. 2007. Etanercept, a review of its use in the management of ankylosing spondylitis and psoriatic arthritis. Drugs, 67:2609-33.

Jacobsson LT, Turesson C, Nilsson JA, et al. 2007. Treatment with TNF blockers and mortality risk in patients with rheumatoid arthritis. Ann Rheum Dis, 66:670-5.

Kapetanovic MC, Saxne T, Nilsson JA, et al. 2007. Influenza vaccination as model for testing immune modulation induced by anti-TNF and methotrexate therapy in rheumatoid arthritis patients. Rheumatology (Oxford), 46:608-11. 
Khanna D, McMahon M, Furst DE. 2004. Anti-tumor necrosis factor alpha therapy and heart failure: what have we learned and where do we go from here? Arthritis Rheum, 50:1040-50.

Khanna M, Shirodkar MA, Gottlieb AB. 2003. Etanercept therapy in patients with autoimmunity and hepatitis C. J Dermatolog Treat, 14:229-32.

Klareskog L, van der Heijde D, de Jager JP, et al. 2004. Therapeutic effect of the combination of etanercept and methotrexate compared with each treatment alone in patients with rheumatoid arthritis: double-blind randomised controlled trial. Lancet, 363:675-81.

Kremer JM, Weinblatt ME, Bankhurst AD, et al. 2003. Etanercept added to background methotrexate therapy in patients with rheumatoid arthritis: continued observations. Arthritis Rheum, 48:1493-9.

Lovell DJ, Giannini EH, Reiff A, et al. 2000. Etanercept in children with polyarticular juvenile rheumatoid arthritis. Pediatric Rheumatology Collaborative Study Group. N Engl J Med, 342:763-9

Lovell DJ, Giannini EH, Reiff A, et al. 2003. Long-term efficacy and safety of etanercept in children with polyarticular-course juvenile rheumatoid arthritis: interim results from an ongoing multicenter, open-label, extended-treatment trial. Arthritis Rheum, 48:218-26.

Lovell DJ, Reiff A, Jones OY, et al. 2006. Long-term safety and efficacy of etanercept in children with polyarticular-course juvenile rheumatoid arthritis. Arthritis Rheum, 54:1987-94.

Mathias SD, Colwell HH, Miller DP, et al. 2000. Health-related quality of life and functional status of patients with rheumatoid arthritis randomly assigned to receive etanercept or placebo. Clin Ther, 22:128-39

Mease PJ, Goffe BS, Metz J, et al. 2000. Etanercept in the treatment of psoriatic arthritis and psoriasis: a randomised trial. Lancet, 356:385-90.

Mease PJ, Kivitz AJ, Burch FX, et al. 2004. Etanercept treatment of psoriatic arthritis: safety, efficacy, and effect on disease progression. Arthritis Rheum, 50:2264-72

Michaud K, Wolfe F. 2007. The effect of methotrexate and anti-tumor necrosis factor therapy on the risk of lymphoma in rheumatoid arthritis in 19,562 patients during 89,710 person-years of observation. Arthritis Rheum, 56:1433-9.

Mohler KM, Torrance DS, Smith CA, et al. 1993. Soluble tumor necrosis factor (TNF) receptors are effective therapeutic agents in lethal endotoxemia and function simultaneously as both TNF carriers and TNF antagonists. J Immunol, 151:1548-61.

Moreland LW, Baumgartner SW, Schiff MH, et al. 1997. Treatment of rheumatoid arthritis with a recombinant human tumor necrosis factor receptor (p75)-Fc fusion protein. $N$ Engl J Med, 337:141-7.

Moreland LW, Schiff MH, Baumgartner SW, et al. 1999. Etanercept therapy in rheumatoid arthritis. A randomized, controlled trial. Ann Intern Med, 130:478-86.

Moreland LW, Weinblatt ME, Keystone EC, et al. 2006. Etanercept treatment in adults with established rheumatoid arthritis: 7 years of clinical experience. J Rheumatol, 33:854-61.

Nestorov, de Vries, Zitnik R. 2004. Comparative pharmacokinetics of etanercept in patients with psoriasis or rheumatoid arthritis [abstract]. $J$ Am Acad Dermatol, 50:P147. Abstract P572.

Okada SK, Siegel JN. 2006. Risk of serious infections and malignancies with anti-TNF antibody therapy in rheumatoid arthritis. JAMA, 296:2201-2.

Rudwaleit M, Listing J, Brandt, J et al. 2004. Prediction of a major clinical response (BASDAI 50) to tumour necrosis factor alpha blockers in ankylosing spondylitis. Ann Rheum Dis, 63:665-70.
Schneeweiss S, Setoguchi S, Weinblatt ME, et al. 2007. Anti-tumor necrosis factor alpha therapy and the risk of serious bacterial infections in elderly patients with rheumatoid arthritis. Arthritis Rheum, 56:1754-64.

Setoguchi S, Solomon DH, Weinblatt ME et al 2006. Tumor necrosis factor alpha antagonist use and cancer in patients with rheumatoid arthritis. Arthritis Rheum, 54:2757-64.

Soriolo B, Paolino S, Sulli A, et al. 2006. Bone metabolism changes during anti-TNF-alpha therapy in patients with active rheumatoid arthritis. Ann NY Acad Sci, 1069:420-7.

Strangfeld A, Listing J. 2006. Infection and musculoskeletal conditions: Bacterial and opportunistic infections during anti-TNF therapy. Best Pract Res Clin Rheumatol, 20:1181-95

Strangfeld A., J. Listing, R. Rau, et al. 2007. Reactivation of herpesviruses (hhv-1 and hhv-3) infections is increased in RA patients treated with adalimumab or infliximab. Ann Rheum Dis, 66(Suppl II):OP0214.

Tubach F, Salmon D, Ravaud P, et al. 2007. Definitive results of the National French prospective RATIO 3-year observatory on tuberculosis inpatients treated with TNF blockers: the risk persists but depends on the drug. Arthritis Rheum, 56:S426.

van der Heijde D, Klareskog L, Landewé R, et al. 2007. Disease remission and sustained halting of radiographic progression with combination etanercept and methotrexate in patients with rheumatoid arthritis. Arthritis Rheum, 56:3928-39.

van der Heijde D, Klareskog L, Singh A, et al. 2006b. Patient reported outcomes in a trial of combination therapy with etanercept and methotrexate for rheumatoid arthritis: the TEMPO trial. Ann Rheum Dis, 65:328-34.

van der Heijde, Klareskog L, Rodriguez-Valverde V, et al. 2006a. Comparison of etanercept and methotrexate, alone and combined, in the treatment of rheumatoid arthritis: two-year clinical and radiographic results from the TEMPO study, a double-blind, randomized trial Arthritis Rheum, 54:1063-74.

van Riel PL, Taggart AJ, Sany J, et al. 2006. Efficacy and safety of combination etanercept and methotrexate versus etanercept alone in patients with rheumatoid arthritis with an inadequate response to methotrexate: the ADORE study. Ann Rheum Dis, 65:1478-83.

Weinblatt M, Combe B, Covucci A, et al. 2006. Safety of the selective costimulation modulator abatacept in rheumatoid arthritis patients receiving background biologic and nonbiologic disease-modifying antirheumatic drugs: A one-year randomized, placebo-controlled study. Arthritis Rheum, 54:2807-16.

Weinblatt ME, Kremer JM, Bankhurst AD, et al. 1999. A trial of etanercept, a recombinant tumor necrosis factor receptor:Fc fusion protein, in patients with rheumatoid arthritis receiving methotrexate. $N$ Engl $J$ Med, 340:253-9.

Wolfe F, Michaud K. 2007. Biologic treatment of rheumatoid arthritis and the risk of malignancy. Analysis from a large US observational study. Arthritis Rheum, 56:2886-95

Woolacott NF, Khadjesari ZC, Bruce IN, et al. 2006. Etanercept and infliximab for the treatment of psoriatic arthritis: a systematic review. Clin Exp Rheumatol, 24:587-93.

Zhou H. 2005. Clinical pharmacokinetics of etanercept: a fully humanized soluble recombinant tumor necrosis factor receptor fusion protein. J Clin Pharmacol, 45:490-7. 
